\section{A descoberta do ambiente biológico}



Por Ricardo Waizbort

Fundação Oswaldo Cruz

(ricardowaizbort@yahoo.com.br)

CAPONI, Gustavo.

La segunda agenda darwiniana: contribución preliminar a una

historia del programa adaptacionista. México,

DF: Centro de Estudios

Filosóficos, Políticos y Sociales Vicente

Lombardo Toledano, 2011. 200 p. ISBN 978607-466-030-2

The significance of an adaptation can only be understood in relation to the total biology of the species.

Julian Huxley

Dizer o tigre é dizer os tigres que o geraram, os cervos e as tartarugas que devorou, o pasto de que se alimentaram os cervos, a terra que foi mãe do pasto, o céu que deu à luz a terra.

Jorge Luis Borges

Óltimo livro do professor de filosofia da Universidade Federal de Santa Catarina (UFSC), Gustavo Caponi, "La segunda agenda darwiniana: contribución preliminar a una historia del programa adaptacionista", produz pelo menos três importantes inversões de perspectiva no leitor com algum conhecimento da história da teoria da evolução por seleção natural. Em primeiro lugar, Caponi defende, ao contrário de estudiosos do adaptacionismo, como Elliott Sober, John Maynard-Smith e Stephen Jay Gould, entre outros, que explicar a adaptação não era o objetivo central do livro de Darwin de 1859, "A origem das espécies". A obra teria como alvo precípuo desenvolver em profundidade o programa filogenético, a primeira agenda darwiniana: traçar as relações genealógicas entre os seres vivos, explicando a diversificação das espécies de animais e plantas a partir do mecanismo da seleção natural.

Gustavo Caponi é argentino da cidade de Rosário e se doutorou em Lógica e Filosofia da Ciência pela Universidade de Campinas (UNICAMP), em 1992. Desde 1993, é docente da Faculdade de Filosofia da UFSC. Ele foi professor visitante em universidades da Colômbia e da França, e pesquisador visitante do Instituto de História e Filosofia das Ciências e das Técnicas, da Sorbonne, França. Como a extensa bibliografia de "La segunda agenda darwiniana" evidencia, Caponi mergulhou fundo na leitura de fontes primárias, certamente em bibliotecas europeias, especialmente francesas, uma vez que essas fontes são escassas no Brasil. E desse mergulho trouxe informações que não só corrigem erros como abrem uma nova perspectiva para compreender o adaptacionismo hoje, como um programa de pesquisa muito bem sucedido. Antes de publicar o livro que ora nos ocupa, Caponi escreveu e publicou cerca de uma centena de artigos, a maioria deles sobre temas de história e filosofia da ciência em geral, e da biologia e evolução em particular, além de dois outros livros, "George Cuvier: un fisiólogo de museo" (México, UNAM, 2008) e "Buffon: breve introducción al pensamiento de Buffon" (México, UAM, 2010). Em "La segunda agenda darwiniana", Caponi faz uso parcial de muitas informações contidas em vários desses artigos e livros precedentes, nos quais trabalha com mais detalhes temas que serão instrumentais para os argumentos que defende no livro de 2011. "La segunda agenda darwiniana", assim como vários artigos, está disponibilizado no sítio da Associação Filosófica Scientiae Studia, no endereço eletrônico http://www.scientiaestudia.org.br/associac/ gustavocaponi/index.asp.

Para Caponi, a explicação do processo de adaptação se manifesta como uma segunda agenda um tanto embrionária no livro de Darwin de 1859. Em realidade, o adaptacionismo de "A origem" estaria restrito a alguns experimentos imaginários e alguns raciocínios adaptativos muito bem elaborados, como é o caso da estrutura e 
dos hábitos alimentares dos pica-paus. Mas teriam sido diferentes naturalistas de campo, como Alfred Russel Wallace, Fritz Müller, Henry Bates e outros menos conhecidos, como Karl Semper e Edward Poulton, entre outros, que tomaram o embrião de Darwin nas próprias mãos, e o cultivaram. Mesmo nas décadas do chamado 'eclipse do darwinismo', aproximadamente entre 1890 e 1920 - na realidade, mais um eclipse da teoria da seleção natural para explicar as adaptações do que efetivamente um eclipse do programa filogenético - foram os naturalistas de campo, com estudos principalmente sobre mimetismo e colorações protetoras, sobretudo em insetos e aves, que procuraram uma razão de ser, uma utilidade para muitos detalhes da forma e do comportamento de animais, que antes pareciam de importância muito marginal, ou mesmo desprovidos de interesse (p. 121-122). Assim, ainda no âmbito da primeira inversão de perspectiva referida no parágrafo inicial dessa resenha, Caponi também combate a ideia propugnada por Richard Lewontin (1982), de que a biologia evolutiva tem sido em grande parte "el desarrollo do programa adaptacionista" (p. 7).

A consolidação desse programa, cujos primórdios se encontram sim em Darwin, só iria ocorrer com o estabelecimento da ecologia como uma ciência com métodos, técnicas e propósitos próprios. A ecologia, ao identificar os detalhes das condições de existência, sobretudo biológica, dos ecossistemas, por definição compostos por populações de espécies muito variadas, procura descobrir no mundo natural as pressões que a luta pela sobrevivência exerce sobre toda e qualquer população, de toda e qualquer espécie de ser vivo. Tais pressões acabariam por produzir, ao longo das gerações, estruturas que a um só tempo estão perfeitamente ajustadas entre si e também ajustadas às duras condições de existência.

A segunda inversão de Caponi é a negação de que haja algo homólogo ao conceito de adaptação antes de Darwin, nos escritos de Paley, Cuvier, Buffon, Lamarck e mesmo de Humboldt, entre (muitos) outros. Nesse caso, autores como Michael Ruse, Arthur Cain e de novo Stephen Jay Gould coincidiriam erroneamente em sustentar que a visão utilitária das estruturas orgânicas, preconizada pelo darwinismo, intimamente relacionada com o tema da adaptação, teria antecedentes na teologia natural e na história natural anterior à publicação de "A origem" (p. 9). Esse é tema do primeiro capítulo, "Contra el mito del adaptacionismo predarwiniano". Desde a introdução, Caponi procura mostrar que, em "A origem das espécies", Darwin compreende o processo de adaptação causado pela seleção natural muito mais como dificuldade e desafio, apontando o imenso trabalho que teria que ser feito para conceber cientificamente um "mecanismo plausible de modificación y diversificación que sea capaz de producir seres cuyas partes estén mutuamente coadaptadas y, por su vez, adaptadas a las exigências ambientales" (p. 1). A mútua coadaptação das partes é um conceito fundamental no argumento que será desenvolvido no capítulo 1. O que foi interpretado por certos historiadores e filósofos da biologia como adaptação ou como estruturas utilitárias antes de Darwin, na verdade diz respeito a essas partes mutuamente coadaptadas, a 'correlação das partes' preconizada por George Cuvier, usada inclusive para defender argumentos anti-evolucionistas. Nenhuma estrutura, digamos uma asa, pode mudar muito sem que implique a mudança de todos os sistemas que se relacionam, direta ou indiretamente, com a asa.

O mito de que existe um adaptacionismo antes de Darwin diminui, na visão de Caponi, a absoluta novidade que o mecanismo da seleção natural trouxe para a história natural. Ele mostra que vários autores anteriores a Darwin, como o próprio Cuvier, mas também evolucionistas como Buffon, Saint-Hillaire e Lamarck, davam pouca atenção ao ambiente em que se encontravam as espécies, e quando o ambiente era referido, o era muito mais em relação aos seus constituintes físicos, e não biológicos. Segundo Caponi, para o evolucionista pré-darwiniano Saint-Hillaire, entre os fatores que exercem influência sobre a forma dos indivíduos estão principalmente: 
"(...) a temperatura, la humedad, los cambios en la presión barométrica, la calma de la atmósfera, los vientos, la pureza del aire, o la presencia de miasmas más o menos deletéreas, y, en fin, el grado habitual de transparencia y serenidad del cielo". Nada ahí remitía a factores específicamente biológicos que pudiesen propiciar y exigir câmbios morfológicos o etológicos en las diferentes espécies (p. 39).

$\mathrm{Na}$ terceira inversão de perspectiva, Caponi nega que a história da teoria da seleção natural possa ser confundida com a história do programa adaptacionista. A teoria da seleção natural voltou a encontrar na Teoria Sintética da Evolução ou Síntese Evolutiva, consolidada nas primeiras décadas do século $X X$ por biólogos de várias formações diferentes, um lugar destacado, depois de seu eclipse. Trata-se da síntese entre a teoria mendeliana da constância dos caracteres ao longo das gerações com a teoria darwiniana da descendência com ligeiras variações esculpidas pela seleção natural, mas que não teria abrangido, por exemplo, campos como a embriologia e a própria ecologia (Mayr e Provine, 1980).

Segundo Caponi, o programa adaptacionista só começaria de fato a se estabelecer como um efetivo programa de pesquisa a partir de meados da década de 1960. Nesse sentido, argumenta e mostra que a história do programa adaptacionista, sobretudo no século $X X$, está para ser contada. "La segunda agenda darwiniana" seria uma contribuição preliminar nesse sentido.

Caponi argumenta, como indica o título do segundo capítulo, "El adaptacionismo como corolário de la teoria de la selección natural", que o processo de adaptação ocorreu a Darwin como uma decorrência lógica do uso da teoria da seleção natural para explicar o processo filogenético da diversificação das espécies. Adaptação é a 'sintonia fina' entre a estrutura dos indivíduos de cada uma das espécies e as duras condições do meio ambiente, onde ocorre a luta pela sobrevivência. Não só asas para voar, nadadeiras para nadar, nem só pulmões para respirar, corações para bombear sangue pelo corpo, olhos para ver, mesmo além de bicos para pegar insetos, cores para se disfarçar entre as plantas ou para enganar predadores: cada detalhe da estrutura de um ser vivo, que lhe seja útil no ambiente em que se encontra, a seleção natural tende a preservar ao longo do tempo. A partir desse princípio de utilidade, cada estrutura e comportamento pode ser interpretado como tendo significado na luta pela existência. A seleção natural foi utilizada, então, para explicar como em ambientes propícios, histórica e ecologicamente específicos, características a princípio apenas ligeiramente vantajosas para seus possuidores seriam, ao longo do tempo, preservadas e desenvolvidas, esculpindo do seio das populações esse ajuste aparentemente perfeito entre o vivente e o seu entorno. E também predizer que condições ambientais pressionam uma espécie para que ela tenha características específicas, pressões essas que devem ser identificadas na natureza para que se justifique a hipótese de que tal ou qual estrutura constitui-se em uma adaptação.

Assim, ao contrário dos trabalhos de teólogos ingleses e naturalistas pré-darwinianos, o estudo da adaptação causada pela seleção natural implicava uma atenção ao ambiente biológico que, antes de 1859, não era sequer suspeitada. Essa atenção ao ambiente derivava de uma síntese conceitual operada por Darwin entre duas escolas de fisiologia opostas: os que aceitavam a doutrina das causas finais, e cujos trabalhos estavam pautados pelo princípio das condições de existência, princípio defendido por George Cuvier; e os que negavam a doutrina das causas finais, cujos trabalhos estavam pautados pela teoria da unidade de plano ou unidade de composição, teoria sustentada por Étienne Geoffroy Saint-Hilaire:

Para Darwin, mientras tanto, esa oposición remitía a dos principios complementarios que estaban contemplados e integrados en su propia teoría: la unidad de tipo explicada por filiación común y el arreglo a las condiciones de existencia explicado por selección natural (...). Cabe destacar, sin embargo, que este último mecanismo hacía algo más que explicar cómo las diferentes especies de seres vivos pudieron originarse a partir de una única forma ancestral, o de un conjunto relativamente pequeño de dichas formas, preservando o reformulando ese arreglo a las condiciones de existencia que ya había sido 
analizado por la historia natural anterior a la revolución darwiniana. Al hacer eso, la teoría de la selección natural nos llevaba a considerar los perfiles de los seres vivos desde una perspectiva inédita y ausente en la historia natural previa a 1859. Esta teoría conducía a tener que aceptar que, haciendo abstracción de las influencias directas del entorno y de los constreñimientos derivados de las correlaciones del crecimiento, esos perfiles debían responder a los más variados desafíos y oportunidades que el ambiente planteaba, o le había planteado, a los diferentes linajes de organismos (grifo meu) (p. 45).

Ou seja, embora haja referência ao ajuste entre a forma do ser vivo e o ambiente antes de Darwin, ninguém antes dele pensara o ambiente como um cenário composto pelos mais variados desafios e oportunidades, como que pressionando a própria estrutura das populações, eliminando os portadores de variações desfavoráveis e preservando os portadores de variações favorecidas no cenário ambiental em questão.

Embora "Los primórdios do programa adaptacionista", título do terceiro capítulo, se encontre, segundo Caponi, principalmente nas referências de Darwin sobre a estrutura do pica-pau - sua interação com outros pica-paus, fêmeas e machos, com árvores e insetos de que se alimentam, com predadores e parasitas, todos constituintes nesse caso do ambiente em que as espécies de pica-pau se encontram -, é o "The Various Contrivances by which Orchids are Fertilised by Insects", livro de 1862, "la verdadera obra fundacional del programa adaptacionista" (p. 84). Darwin analisa nesse livro conformações florais de distintas espécies de orquídeas, considerando-as como recursos adaptativos relacionados à fertilização. Ou seja, as formas das orquídeas são artifícios (contrivances) das orquídeas para atrair insetos que levam em seus corpos o pólen para fecundar outras orquídeas. Na capa de "La segunda agenda darwiniana" há a fotografia de uma orquídea, uma Ophrys apifera, que atrai abelhas macho (zangões) tanto por sua forma quanto por seu cheiro.

Nesse terceiro capítulo, Caponi oferece uma releitura de naturalistas que seguiram o raciocínio de
Darwin sobre as adaptações. Ele considera que foram Alfred Wallace e Edward Poulton os que levaram a cabo, mais sistematicamente, o desenvolvimento do adaptacionismo. Caponi também oferece uma releitura de Bates e Müller, assim como de outros naturalistas, incluindo amadores, para mostrar a função fundamental que a categoria de ambiente biológico passa a exercer nessas investigações. Tais naturalistas produziram trabalhos a partir de observações de campo, predominantemente sobre mimetismo e colorações, que se transformariam em evidências do adaptacionismo. Sobretudo as colorações de animais, e também de plantas, pois as cores, a princípio, pareciam ser manifestações não essenciais, desprovidas de grande utilidade. Todavia, seu estudo mostrou que tais cores executam funções decisivas na vida e na reprodução dos indivíduos tocados por elas.

Aos poucos, a partir da revolução darwiniana, os naturalistas de campo passaram a ter proeminência sobre os naturalistas de museu, por sua experiência no mundo natural e selvagem, por seu cuidado em observar aquilo que não poderia ser visto nos museus e gabinetes por fisiologistas e anatomistas. Todavia, como procura demonstrar Caponi: "La batalla por la selección natural se ganó en el campo de los conceptos y en los laboratorios; no se decidió donde la trataron de sorprender y poner en evidencia los naturalistas de campo" (p. 126). 0 programa adaptacionista teve que esperar que a ecologia se desenvolvesse como ciência para que pudesse recrutar métodos, técnicas e conceitos ecológicos, a fim de poder divisar aquelas pressões seletivas que presidiriam a sintonia fina entre a estrutura do vivente e o entorno ambiental. Esse é o tema do quarto e último capítulo do livro, "La consolidación del programa adaptacionista".

Caponi divisa três vetores do conhecimento biológico que convergiram no programa adaptacionista e conduziram à sua consolidação: 1) o vetor iniciado por Darwin e desenvolvido por Wallace e Poulton; 2) o vetor da genética ecológica de populações; 3 ) o vetor da ecologia evolutiva. Os dois últimos vetores são realizações




do século $X X$ e Caponi expõe os trabalhos de alguns de seus mais importantes atores, mostrando também como o adaptacionismo foi obrigado a se confrontar com críticos que apontavam, sobretudo, que muitas características dos seres vivos poderiam não ser adaptativas, ou seja, resultado da seleção natural. Mas exatamente, segundo Caponi, pela mediação de ecologistas que se atreveram a usar seus conhecimentos e métodos para introduzir a perspectiva evolutiva em sua própria disciplina, e pela repercussão de trabalhos ecológicos sobre a própria biologia evolutiva, que a segunda agenda de Darwin pôde chegar à forma e ao alcance que tem hoje (p. 121).

Em 1979, o paleontólogo Stephen Jay Gould e o geneticista Richard Lewontin escreveram um artigo que até hoje causa controvérsias no seio de comunidades científicas: "The Spandrels of San Marco and the Panglossian Paradigm: a critique of the Adaptationist Programme" (Gould e Lewontin, 1979). O artigo começa dizendo que nos últimos quarenta anos (da perspectiva de 1979) o pensamento adaptacionista teria dominado a biologia evolutiva. E que tal programa estaria baseado na fé do poder da seleção natural como um agente otimizador de estruturas e comportamentos biológicos. Caponi conduz a conclusão de seu livro na direção contrária, ao mostrar que a síntese entre teorias ecológicas e evolutivas permitiu o desenvolvimento de formas de testar empiricamente narrativas históricas a respeito da evolução de qualquer linhagem específica. $\bigcirc$ programa adaptacionista procura reconstruir as pressões seletivas, ambientais, para as quais as estruturas dos seres vivos podem ser interpretadas como resposta. Gould e Lewontin argumentaram que as narrativas adaptacionistas são, no mais das vezes, apenas histórias, narrativas (just-so-stories). Para Darwin, para Caponi e para muitos outros cientistas, historiadores e filósofos, como Robert Richards (1998) e David Hull (1998), narrativas estão no próprio âmago das ciências históricas, como a biologia evolutiva. Trata-se, no caso de uma estrutura (ou comportamento) útil qualquer, de reconstruir um cenário presente ou passado que permita entender tal estrutura como resposta populacional ao ambiente. Como expressa o título de um trabalho de David Hull (1998), as espécies podem ser entendidas como atores genealógicos em um palco ecológico. Ocorre que o próprio palco ecológico é formado não só pelas condições físicas do ambiente, mas sobretudo pelos componentes biológicos que são os outros indivíduos (seja da mesma ou de diferentes espécies) com que cada ser vivo, de qualquer espécie, está obrigado a interagir. E, mais uma vez, muitas, muitas adaptações podem ser vistas como respostas às condições desse emaranhado que a todos nos envolve, e testadas como tais. Nesse sentido, a narrativa de "La segunda agenda" mostra que erros históricos podem levar a importantes equívocos epistemológicos, como o de considerar o adaptacionismo um programa de pesquisa hegemônico e totalizador. E os prejuízos causados por esses deslizes são pagos pelas gerações que repetem tais erros, estagnadas no tempo, enquanto as espécies continuam sua dança ao som e à fúria do ambiente biológico.

\section{REFERÊNCIAS}

GOULD, Stephen Jay; LEWONTIN, Richard. The Spandrels of San Marco and the Panglossian Paradigm: a critique of the Adaptationist Programme. Proceedings of the Royal Society of London, Series B, Biological Sciences, v. 205, n. 1161, p. 581-598, 1979.

HULL, David. Sujetos centrales y narraciones historicas. In: MARTINEZ, Sergio; BARAHONA, Ana (Comp.). Historia y explicación en biologia. México, DF: Fondo de Cultura Economica, 1998. p. 247-272.

LEWONTIN, Richard. La adaptación. In: LEWONTIN, Richard (Ed.). Los libros de Investigación y Ciencia: Evolución. Barcelona: Labor, 1982. p. 139-152.

MAYR, Ernst; PROVINE, William B. (Eds). The evolutionary synthesis: perspectives on the unification of biology. Cambridge: Harvard University Press, 1980.

RICHARDS, Robert. La estructura de la explicacion narrativa en historia y biologia. In: MARTINEZ, Sergio; BARAHONA, Ana (Comp.). Historia y explicación en biologia. México, DF: Fondo de Cultura Economica, 1998. p. 212-246. 